NASZA DERMATOLOGIA Onlin OUR DERMATOLOGY Online Nil

Competing Interests: None

\section{FACIAL SPOROTRICHOSIS IN CHILDREN FROM ENDEMIC AREA IN PERU}

\author{
Max Carlos Ramírez Soto
}

Clinical Pathology Service, Santa Teresa Clinic of Abancay, Apurímac, Peru

Corresponding author: Dr. Max Carlos Ramírez Soto

maxcrs22@gmail.com
Sporotrichosis is a subcutaneous mycosis subacute or chronic evolution, caused by the dimorphic Sporothrix complex, which includes five species: Sporothrix albicans, Sporothrix brasiliensis, Sporothrix globosa, Sporothrix mexicana and Sporothrix schenckii (sensu stricto). The infection occurs after trauma with contaminated material, which inoculated the fungus on the skin. The clinical types of sporotrichosis are lymphocutaneous sporotrichosis, fixed cutaneous (nodulopapular, ulcerative, verrucouse and furunculoide) and extracutaneous [1,2]. It is a mycosis of a universal distribution, but more commonly seen in tropical or subtropical countries. The majority of cases are found in Mexico, Central America and Peru [1]. However, the region of Abancay in Peru is considered hyperendemic and has an annual incidence of 48-60 cases per 100000 population [3]. Also, the incidence is three times higher in children aged $0-14$ in $\geq 15$ years of age, approximately 1 case/ 1000 children $0-14$ years and a frequency of $60 \%$ [4,5]. In pediatric patients from endemic areas the most anatomical site affected is the facial region $(40-42 \%)[5,6]$, with lesions on the nose, face, chin, malar, genian and palpebral that is clinically rarely mentioned in the literature [7].

\section{Diagnosis:}

The gold standard for diagnosis is the mycological culture of secretions from injuries. In the crop in Sabouraud dextrose agar with chloramphenicol at $25^{\circ} \mathrm{C}$ colonies are observed finely radiated creamy white and brown. Lactophenol blue stained observed microscopically thin and branched hifas. In $\mathrm{BHI}$ agar at $37^{\circ} \mathrm{C}$ are observed yeast creamy, moist, and whitish. Microscopically with oval and globular structures [1].

\section{Treatment:}

In our experience treatment with potassium iodide in the form of saturated (SSKI) at doses of 2-20 drops / 3 times / day is preferred for pediatric cases and lymphocutaneous fixed cutaneous form [5]. Other treatment options are oral imidazole, ketoconazole, itraconazole or fluconazole and terbinafine at standard doses with favorable response in terms of three to five months of continuous administration [1]. We present photographs of pediatric patients with cutaneous sporotrichosis fixed facial skin and lymphatic topographical characteristics can be useful to be considered in the differential diagnosis against other infections in children from endemic areas also are images of the etiologic agent Sporothrix schenckii. The photographs were obtained from patients treated at Santa Teresa Clinic of Abancay, Peru.

Ethical considerations: For taking photographs and publishing these. Informed consent was obtained in writing and signed by the parents of the patients. Figures 3, 4 and 5 represent the palpebral forms sporotrichosis. Magazines were published previously in Peru $[5,6,8]$.

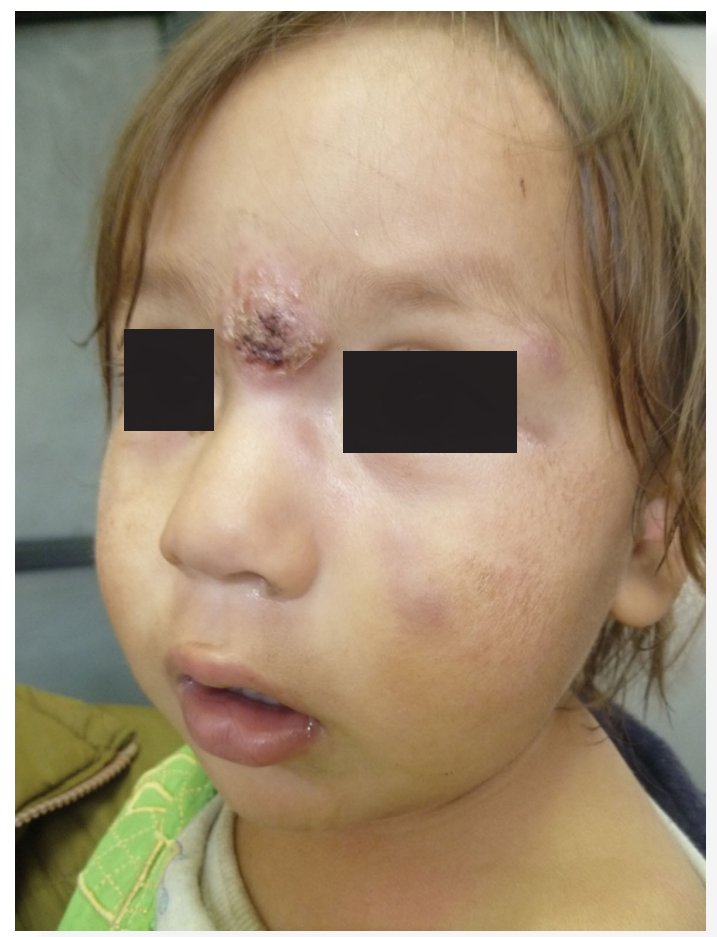

Figure 1. Cutaneous lymphatic sporotrichosis crusted-ulcer on the forehead and nose with nodules on the cheeks 


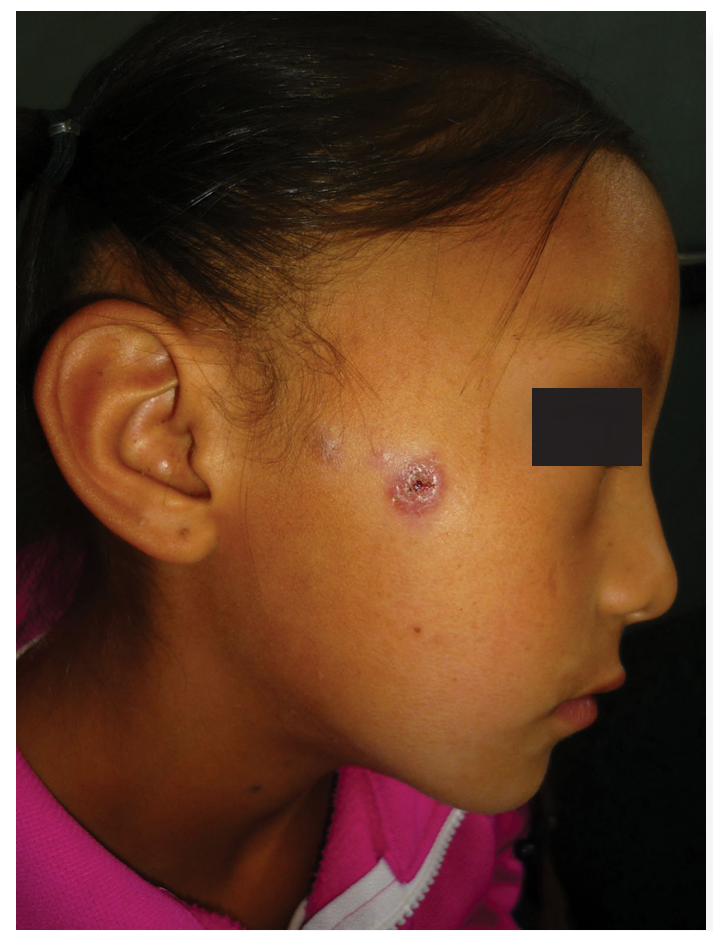

Figure 2. Sporotrichosis lymphocutaneous on the malar region

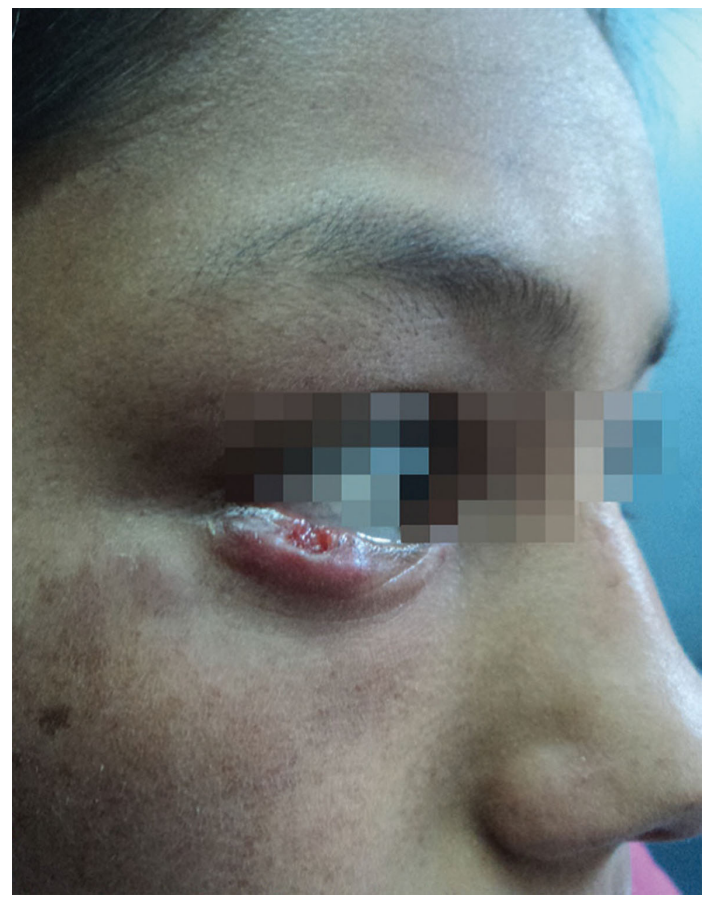

Figure 4. Ulcerated cutaneous lymphatic sporotrichosis in the right lower eyelid with nodules in the malar region

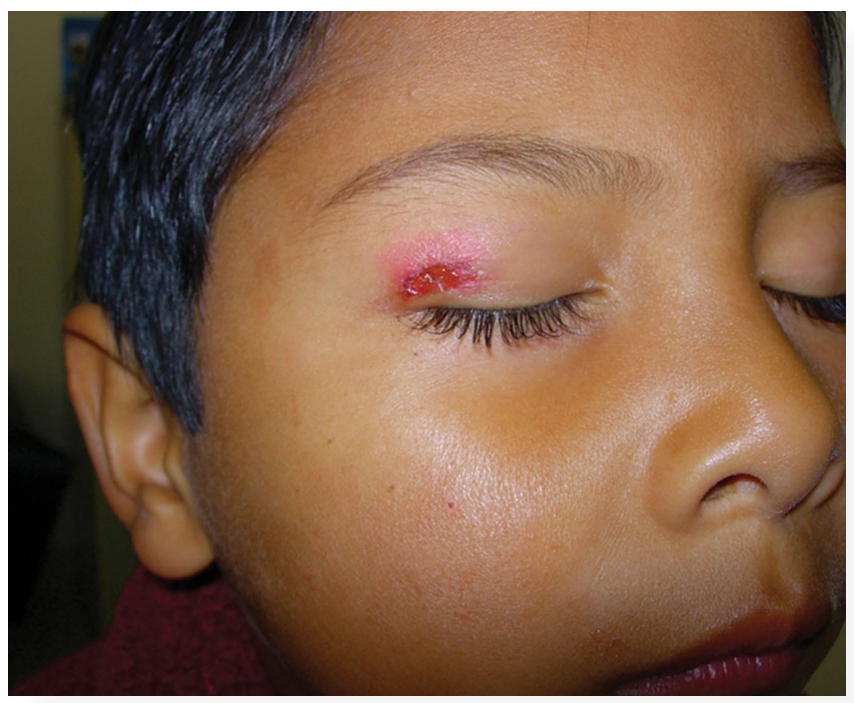

Figure 3. Fixed cutaneous sporotrichosis ulcerated right upper eyelid

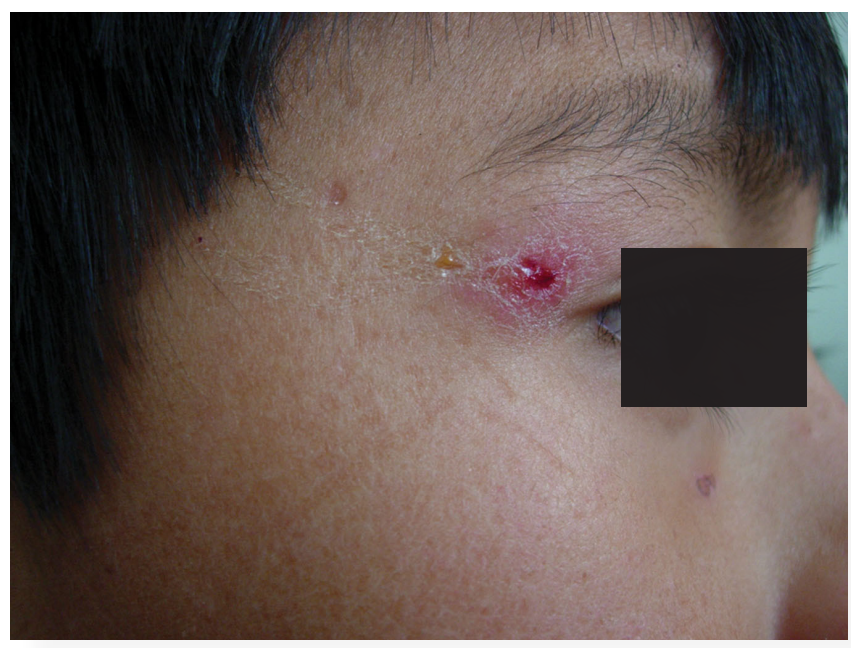

Figure 5. Fixed cutaneous sporotrichosis right upper eyelid

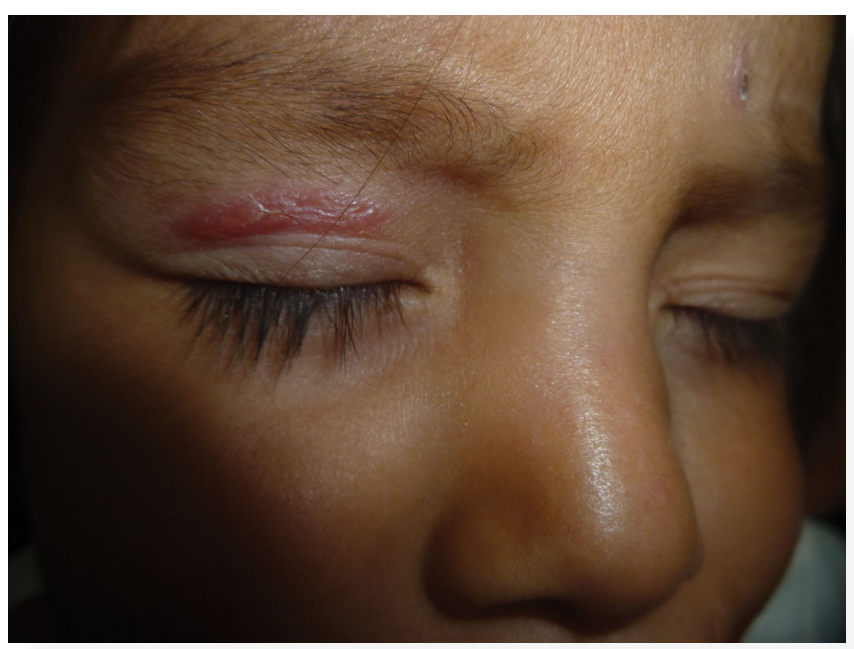

Figure 6. Palpebral fixed cutaneous sporotrichosis in child of two years old 


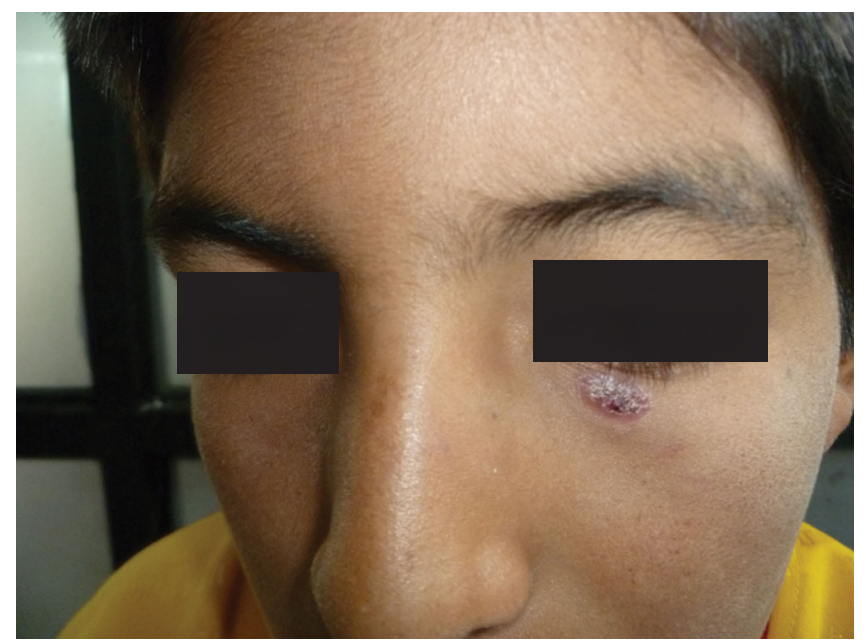

Figure 7. Fixed cutaneous sporotrichosis left lower eyelid

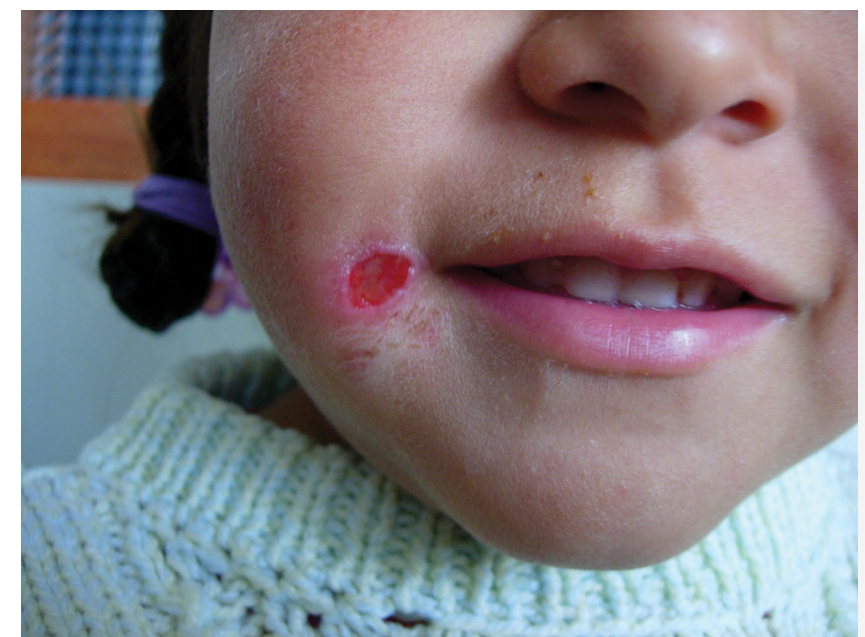

Figure 9. Fixed cutaneous sporotrichosis ulcerative the genian region
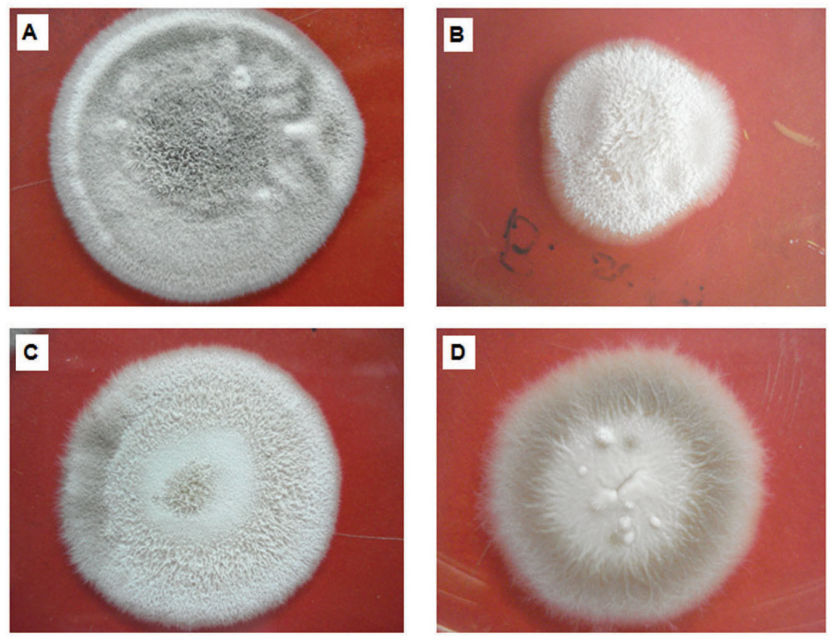

Figure 11. Sporothrix schenckii cultivation on Sabouraud dextrose agar with chloramphenicol at $25^{\circ} \mathrm{C}$, colonies are observed with different shapes, white and brown finely grooved radiated

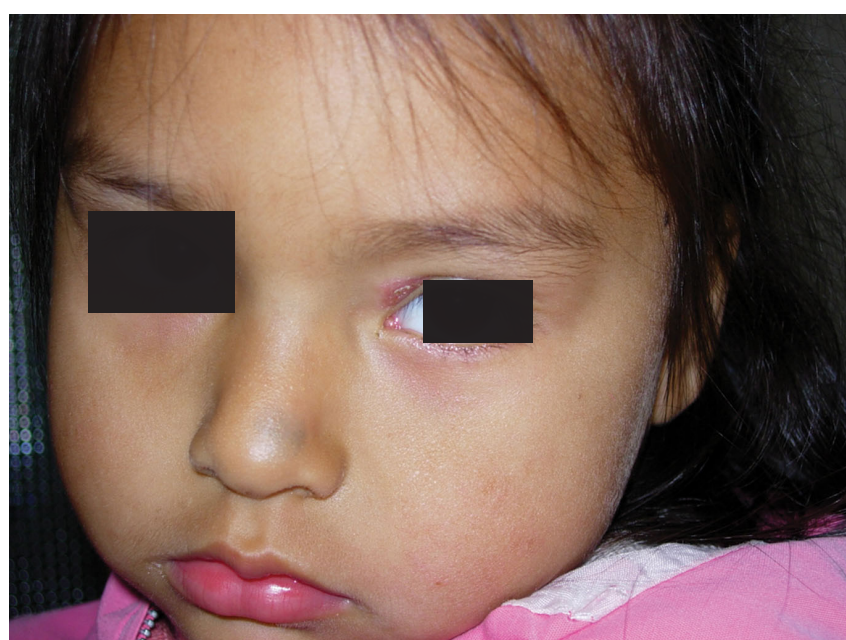

Figure 8. Fixed cutaneous sporotrichosis left upper eyelid

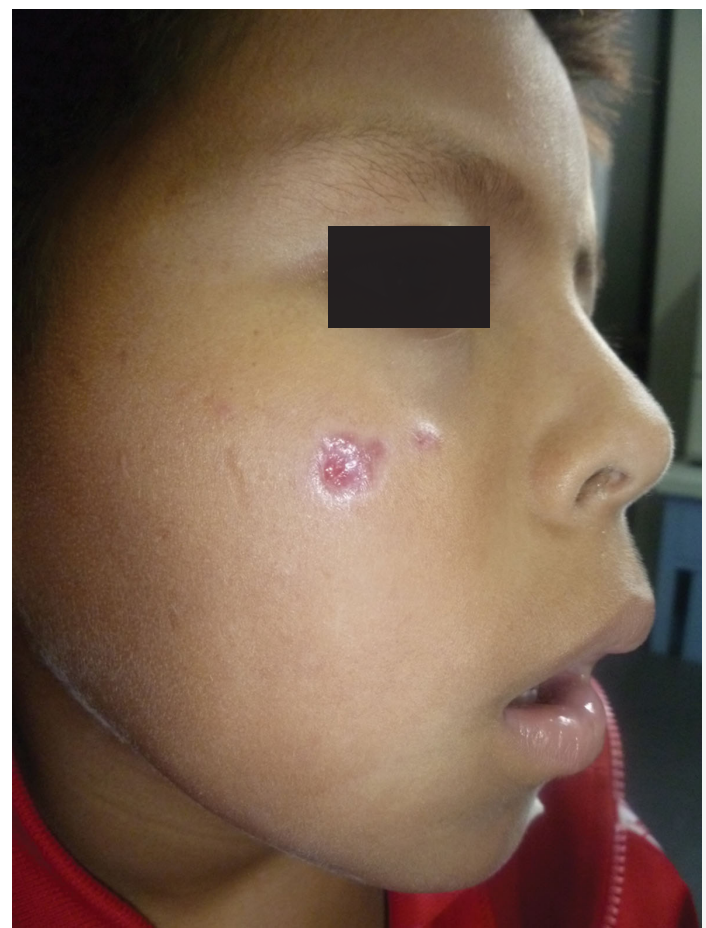

Figure 10. Fixed cutaneous sporotrichosis satellitosis cheek 

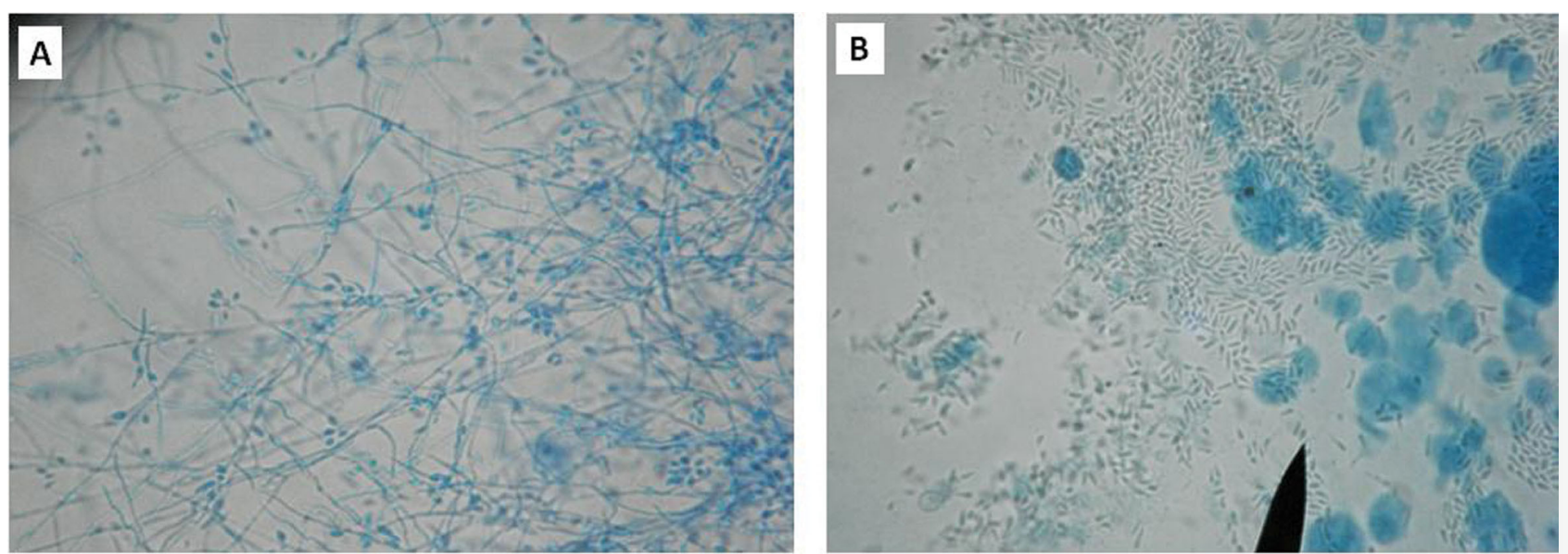

Figure 12. Photomicrograph of Sporothrix schenckii: A. Mycelial form: displayed twisted hifas with microconidia; lactophenol blue staining. B. Parasitic form: Yeast is observed in the form of cigar

\section{REFERENCES}

1. Marimon R, Cano J, Gené J, Sutton DA, Kawasaki M, Guarro J: Sporothrix brasiliensis, S. globosa, and S. mexicana, three new Sporothrix species of clinical interest. J Clin Microbiol. 2007;45:3198-206.

2. Arenas R: Micología Médica Ilustrada 3a ed. McGraw-Hill Interamericana. 2008;p:149-59.

3. Papas PG, Tellez I, Deep AE, Nolasco D, Holgado W, Bustamante B: Sporotrichosis in Peru: description of an área of hyperendemicity. Clin Infect Dis. 2000;30:65-70.

4. Lyon G, Zurita S, Casquero J, Holgado W, Guevara J, Brandt M, et al: Population-based surveillance and a case-control study of risk factors for endemic lymphocutaneous sporotrichosis in Peru. Clin Infect Dis. 2003;36:34-9.
5. Ramírez-Soto M, Lizarraga-Trujillo J, Ticona-Sánchez E, Carrión-León O, Borda-López S: Perfil clínico-epidemiológico de esporotricosis en una clínica de referencia en Abancay, Perú: 20042011. Rev peru epidemiol. 2012;16:121-26.

6. Ramírez Soto MC, Andagua Castro J, Lizarraga Trujillo J, Aguilar Ancori EG, Pezo Ochoa JD: Sporotrichosis in patients attending a reference center in Abancay, Peru. Rev Perú Med Exp Salúd Pública. 2011; 28(3): 508-12.

7. Miranda H. Características clínicas e incidencia de la esporotricosis palpebral: comunicación de 16 casos nuevos. Folia Dermatol Peru. 2006;17:9-15.

8. Ramírez-Soto MC, Loayza-Calderón M: Esporotricosis polimórfica, un problema de salud pública que debemos valorar. Acta Med Per. 2012;29:128-31.

Copyright by Max Carlos Ramirez Soto. This is an open access article distributed under the terms of the Creative Commons Attribution License, which permits unrestricted use, distribution, and reproduction in any medium, provided the original author and source are credited. 